A Clinician's View of Neuromuscular Diseases 2nd edition. By Brooke. (£38.00.) London: Williams and Wilkins. 1986.

This book, which has now reached its second edition, gives clear and detailed clinical descriptions of neuromuscular diseases. Any book whose introduction starts with an apology that it is not an 'Encyclopaedic Compendium' but rather a practical guide for the practising clinician is to be welcomed. The style is very readable and I am sure that it will be, and indeed has been, used by neurologists, paediatricians, and clinical geneticists on a day to day basis.

The chapter on symptoms and signs gives an accurate and concise guide to the assessment of the patient with neuromuscular disease. The description of the deterioration of the boy with Duchenne dystrophy is very valuable as is the author's precis of all the research into the causation of this sad disease. In this chapter the genetic aspects are well covered with a realisation that research is likely to overtake present advice on carrier detection and prenatal detection. Nevertheless advice on genetic risks is rather harder to find in some other sections of the book.

This book is a good guide to the physical management of children with muscle disease; however, there is little on the home adaptations which make such a difference to the lives of patients and their families. There is also little on educational options for these children. The presentation of the book is spoilt slightly by the lack of paragraph headings which makes it difficult to find information quickly in some of the longer chapters. Despite these rather minor points this is a splendid book which will be of use to the practising clinician. There are few fields where accurate diagnosis is as important as neuromuscular disease in giving genetic advice. This book makes that accurate diagnosis easier and will therefore be of particular value to the clinical geneticist.

J R SiberT

\section{The Man Behind the Syndrome}

By Peter Beighton and Greta Beighton. (Pp 240; £19.90.) Berlin: Springer-Verlag. 1986.

Physicians and surgeons have had bibliographical details of their notables enshrined in various texts for several years, and now geneticists have theirs. Here are presented details of those who have achieved ".... eponymous immortality or notoriety" for disorders and syndromes which have a significant genetic or chromosomal basis. The book is divide into two sections. In the first, a photograph of portrait is provided for each of 100 persons, most of whom are dead, or in the case of Klein, Refsum듬. Rieger, and Wiedemann have "...reached sucl? seniority that professional jealousy is unlikely to be aroused in their colleagues". Few would take issue्छ with the inclusion of any in this section, of whom incidentally only three are women (Julia Bell: Cornelia de Lange, and Gertrud Hurler). The mear age at death in this group is 71 (SD 12) whic suggests that having one's name eponymously asso ciated leads to good survival! There are, howeverin notable exceptions: Laurence (of Laurence-Moor r syndrome) died at 42 and Pompe was executed a $\overrightarrow{5}$ the age of 44 for being a member of the Dutclip resistance movement.

The second section contains brief bibliographica 9 information on 110 others, many of whom are stilt active and some might doubt if all these suggested eponyms will survive the passage of time.

Professor Beighton and his wife have produced scholarly work which is delightfully written and welt referenced and will be especially valuable to aldo those with interests in the history of genetics.

\section{Alan E H EMER}

Malformations in Children from One to Seven Years? A Report from the Collaborative Perinatal Projec $\overline{\hat{B}}$ By Ntinos C Myrianthopoulos. (Pp 250; £55.00. New York: Alan R Liss. 1985.

This book is a report on a longitudinal study o congenital malformations in children up to the seventh year of life. There was a previous reporis after one year on the same cohort. Ascertainment of the children was from 12 institutions throughout the USA, in the Collaborative Perinatal Project of the National Institute of Neurological and CommunicaO tive Disorders and Stroke. The sample size was 5 229 consecutive single births with known outcome. including fetal and neonatal deaths. The first third of the book is devoted to criteria and definitions. sources of data, plan of the work, and discussions o中 malformations detected from one to seven years and comparison with those detected in the first yea黑 study. Racial and sex differences are examined. The section on malformations detected after the age oळ one year is of interest, as is the follow up informa? tion on children found to have a particular ma! formation at one year, since this gives some in formation on prognosis. Two-thirds of the book devoted to detailed appendices where the numbers of individual malformations are given and the 
distribution between white and black probands, and between male and female probands. It is helpful in this section that distinction is made between a malformation occurring as an individual finding and where it is part of a multiple malformation pattern.

This book will mainly be of interest to epidemiologists with an interest in congenital malformations, but clinical geneticists and paediatricians interested in congenital malformations will also find much of value here. In other, largely epidemiological, studies it is frustrating for a clinician interested in diagnoses in individual cases to try and work out which malformations were linked together in a single child. However, this report contains supplementary information about individual cases and helpful details are given about associations of various malformations. The study certainly demonstrates the value of a longitudinal study, since it showed that significantly more children had malformations detected during the period from one to seven years than were found in the first year of life. It demonstrates the potential value of an 'active' congenital malformation register to those involved in planning services.

Dian DonnaI

\section{The Hemoglobinopathies}

Methods in Hematology Volume 15. Edited by T H J Huisman. (Pp 200; £35.00.) Edinburgh, London: Churchill Livingstone. 1986.

The editor of a previous volume of this series described writing a book devoted to laboratory methods as having "about the same intellectual and emotional appeal as copying out a telephone directory". One can sympathise with this view, but as this series has shown, when done properly the result is extremely useful and this current volume lives up to its predecessors. There is no substitute for extensive experience to know a technique inside out and few can surpass Titus Huisman and his team of authors in the haemoglobinopathy field.

The format combines background information, step by step recipes, interpretation of results, and comments on the problems likely to be encountered. Basic techniques, such as measuring $\mathrm{Hb} \mathrm{A}_{2}$ and $\mathrm{F}$ and detecting unstable haemoglobins, are extensively covered, as are more recent techniques requiring sophisticated (and expensive) equipment for high pressure liquid chromatography and isoelectric focusing. Both novitiates and more experienced workers are likely to benefit, although perhaps a chapter on detecting haemoglobino- pathies for those on a limited budget would have widened the book's appeal to those in developing countries.

I found very few mistakes - missing decimal points in figure 4.1 lead to persons with $50 \% \mathrm{Hb}$ $\mathrm{A}_{2}$ - although the quality of some of the tone illustrations could have been better. The chapter on oxygen equilibrium measurements is excellent but it is a pity that the advantages of the complex apparatus used were not compared with the more common, but limited, commercially available ones. These are minor criticisms, however, in what is a useful laboratory handbook which should also increase understanding of the methods involved. The final section, a listing of the more than 450 haemoglobin variants described to date, shows how valuable these methods have been. It also reminds us of how necessary telephone directories are.

W G WOOD

\section{Evolution from Molecules to Men}

Edited by D S Bendall. (Pp 594; £12.95.) Cambridge: Cambridge University Press. 1983. (Paperback edition 1985.)

There is no doubt that Darwin, and of course Wallace, revolutionised the thinking of biologists at first morphologists and anatomists, but more recently molecular biologists and ethologists. This current volume is concerned with these various issues and took origin in a conference held in Darwin College, Cambridge, in 1982.

The text consists of some 26 chapters, divided into four sections: The history of evolutionary theory, Molecular and cellular evolution, Evolution of the whole organism, and Evolution of social behaviour. Those chapters dealing with the evolution of gene families and clusters, population genetics, and human evolution, will probably be of most direct interest to medical geneticists. But there is much more. Many contentious issues are considered: is macroevolution merely an extension of microevolution, and how far is behaviour so influenced; how relevant are such concepts as altruism and selfish DNA in the context of evolution? Furthermore, is the theory little more than a successful metaphysical research programme or at worst a series of tautologies and that those species which are capable of reproducing themselves will succeed while those that cannot will die out? These concepts are put in perspective in an epilogue by Passmore, a philosopher, which biologists already versed in evolutionary theory might profitably read after Sir Andrew 